\title{
Artificial Intelligence and Machine Learning in Waste Management and Recycling
}

\author{
Alim Al Ayub Ahmed ${ }^{1 *}$, ABM Asadullah ${ }^{2}$ \\ ${ }^{1}$ School of Accounting, Jiujiang University, Jiujiang, Jiangxi, CHINA \\ ${ }^{2}$ Kulliyyah of Economics and Management Sciences, International Islamic University Malaysia (IIUM), MALAYSIA \\ *Corresponding Contact: \\ Email: alim@jju.edu.cn
}

\begin{abstract}
Waste management is one of the biggest problems facing the world in any developed or developing country. An important aspect of waste management is that the waste bin in the open space is properly filled before the next cleaning process begins. This can eventually lead to various hazards such as dirt and bad odor in the area, which can lead to the spread of various diseases. Population growth has significantly reduced toilets through the waste management system. Laying garbage in public places creates a polluted environment. To eliminate or reduce waste and maintain good hygiene, it requires a waste-based waste management system. The need for proper waste management is not limited to proper collection and disposal of waste. It continues to be a waste disposal and recyclable level. Recycling is considered a major benefit because in addition to waste disposal, our reliance on immature materials is declining. By recycling metal, plastic and glass, the use of decomposing waste can extend beyond compost and manure. Metals can be reused and plastic can be mixed with clay filler, which can lead to soil compaction. After deep cleaning the glass construction material can be broken down and re-melted into new articles. This article is about machine learning and the use of artificial intelligence in the most viable areas and understanding the full need for human communication.
\end{abstract}

Key words:

Artificial Intelligence, Recycling, Waste Management, Sustainability

\section{INTRODUCTION}

To know that a good portion of the waste generated in big cities can be recycled, you need to know the recycling methods that can bring benefits and use them or at least reduce environmental problems. It is now important to have waste disposal technology or models available for proper disposal of such materials. Despite the wide variety of recycling, people 
may be confused as how to find the right garbage place for each disposal. To reduce the impact of improper waste disposal, we propose to use automation based on neurological network strategies aimed at effectively separating domestic (i.e., paper, plastic, glass and junk) waste into recycling stages. The way humans have managed solid waste for centuries still depends on the original plan. Population growth has played a key role in increasing the production of those garments. Therefore, waste control must be reduced individually to maintain balance (Islam et al. 2012). Waste management and functional testing play an important role in sustainable global environmental development. Reducing waste piles by recycling waste is important to society. Good selection filters are often used to improve recycling and reduce environmental impact (Donepudi, 2018). This problem is particularly noticeable in developing countries, where waste management is a major problem in their urbanization and economic development.

\section{LITERATURE REVIEW}

Garbage disposal has become a major problem worldwide due to uncontrolled waste disposal from homes and businesses without effective and efficient waste management systems that can lead to health hazards and adverse environmental impacts (Islam et al. 2012). Good waste management plays an important role in environmental development. Selected collections are often used to improve recycling and reduce environmental impact (Donepudi, 2015), Waste management is a major issue for economic growth, especially in developing countries. Over the years, many measures have been taken to reduce the impact of uncontrolled waste disposal. Technologies such as Radio Frequency Identification Ration (RFID) and Sensor Network (SN) have been used to provide a new way to use waste management methods (Donepudi, 2017). Waste management is a major issue for economic growth, especially in developing countries. Over the years, a number of measures have been used to reduce the impact of uncontrolled waste disposal. Technologies such as Radio Frequency Identification (RFID) and Sensor Network (SN) have been used to provide a new way to improve waste management systems that have proposed a way to improve waste quality following urban waste, each waste generating RFID is stored in tags and the tags are read to provide specific information during the RFID waste processing step. (Abdoli, 2009) The authors discussed RFID technology and product self-regulation, emphasizing serious waste management for its impact and environmental impact, and identifying each drum from the RFID code. Chowdhury \& Chowdhury (2007) developed an RFID sensor that measures the performance of each package and the weight of non-recyclable waste in the garbage truck (which includes the drum and identifies each drum owner). Parlikad \& McFarlane (2007) use RFID tags in their products, which provide information to recycling service providers to assist in making informed decisions about the treatment for that product. Thomas (2008) discusses a reduction and funding scheme to promote human commitment to RFID use and testing in waste management. At this stage, the submitted activities are based on issues such as identifying, monitoring and analyzing discarded waste to enhance appropriate human behavior in selected collections. Sinha \& Couderc (2012) have developed a method for selecting containers for disposal of recyclable waste. Introduced a model using the Ontology Web Language (OWL) to filter smart waste for reuse. They use OWL dynamics to indicate information about the number of recyclable materials in each waste. . , And the Transforming Neurological Network (CNN). Their methods achieved $63 \%$ and $22 \%$ accuracy with SVM and CNN training, respectively. In the same work, Awe et al. (2017) suggested a method to separate different wastes. With three 
stages of the discarded image (e.g. recycled earth and paper) using the Regional Convulsive Neural Networks (Quick R-CNN) process to obtain regional proposals and subdivisions.

\section{ARTIFICIAL INTELLIGENCE BASED SORTING TECHNIQUES}

Waste filtration is important to provide a way to recycle. There are many ways to filter waste that accurately reflect the cost and size of the product. Source segregation consists of the classification of waste produced and recycled materials. It is considered to be the best waste disposal material by hand. The waste scattering method shows that more than $25 \%$ of the positive growth potential can be detected. On the other hand, in order to process proper garbage, it usually requires more staff. This automated process is the best use of technology and energy to prevent the risk of human disorders and respiratory and skin diseases. This is a very high investment with a waste disposal rate of only $15 \%$. We recommend using the introductory machine learning algorithm here, which can greatly change simple techniques and success levels. The machine import algorithm combines new and existing conditions and predictors to suit changing conditions. One of its biggest advantages is that it can integrate even the most unrelated and sensitive sensor information into the decision-making process. Over time, the efficiency of the import system can be surpassed by a more sophisticated system, which is blocked by a code that is rarely available through the knowledge base.

Sensor detector and database assemblers are PC-powered computers that can operate independently. This machine is trained to detect glass, metal and plastic objects using different shapes, degradation levels, sizes, colors and different levels of contamination. Each object goes through a different sensory nerve sequence. The answers associated with them are recorded and an integrated database is created. All containers are evaluated using objectives. The user package parameters determine the comparison and application of the user import algorithms. After developing the proposed models, sensored details are sent to the researcher to question the accuracy and consistency.

The machine learning algorithm is designed to learn how to perform a given task based on reloaded data and pre-set examples. This is called the learning model. It has the ability to read its own response from nature depending on the direct connection. This is called the machine learning principle driven principle. We would like to discuss the case studies that the user needs to establish a list of possible situations during machine code training. Examples provided in the system are usually vector with input variables and output variables. The learning algorithm is designed to create a work or pattern that can draw dynamic output extensions. The visual characteristics of this waste removal sample are container such as size, color, sound properties and visual acuity. It acts as a variant of the input model. Container information can define the material from which the material is obtained and other inputs related to the waste collection date. It acts as a direct link to the system output. The result is the cutting of the trash cans that send each waste. After feeding the machine with a sufficient number of examples, a model-driven learning algorithm is used to generate the integration function. The method of learning and the relevant parameters are determined by the system. This is important for the accuracy, speed and durability of the output. 


\section{Robot Uses Al to SoRt Recyclables}

In 2011, the Finnish company Zen Robotics first appeared in its waste management and robotic waste classification. Their project uses a combination of computer vision, machine learning and artificial intelligence (AI) to use related robotic weapons to filter and retrieve recycled materials from mobile conveyor belts. Learning AI from real-time feeds that provide information from metal sensors, 3D laser cameras and display cameras, selecting and fitting appropriate band material and integrating non-reusable channels into the neural network.

Resource Recycling compiled data from major players in the North American robots business AMP, BHS, Machinex and ZenRobotics, and we supplemented the data with information obtained from news sources and past reports.

Table 1: Number of Robots sold or installed in North America

\begin{tabular}{|l|c|c|}
\hline Robot type & Number of systems & Number of facilities \\
\hline Bulk handling systems (BHS) & 49 & 16 \\
\hline AMP & 25 & 13 \\
\hline Machinex & 8 & 5 \\
\hline Zen Robotics & 6 & 3 \\
\hline
\end{tabular}

Then came Spain. Sadako Technologies is working on AI-based waste disposal projects at a lower rate than General Robotics. The company also uses related policies to connect to a multi-layer network that lives in the cloud.

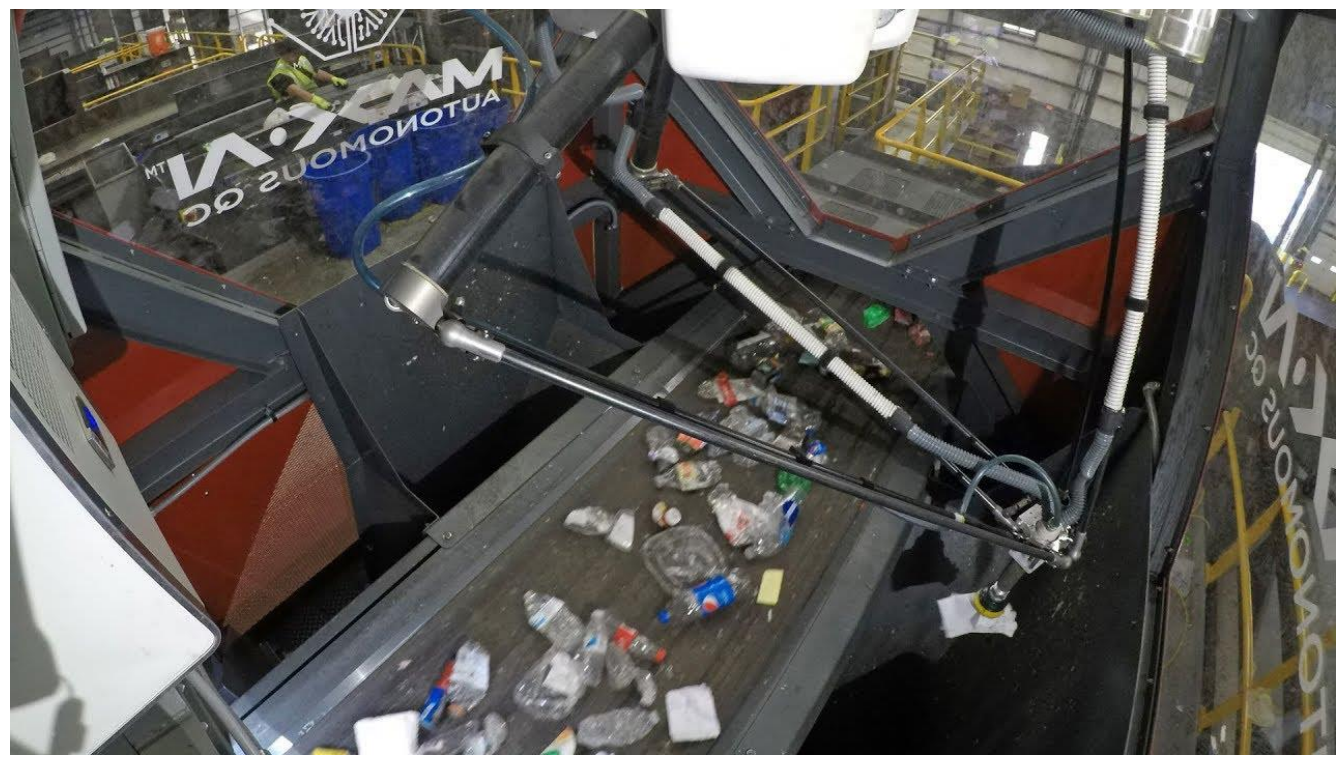

Figure 1: Robot uses AI to Sort Recyclables

Now, Clark has a redesigned robot that uses AI to locate boxes for a wide variety of food and beverages, so it can be caught and separated from all other applications. According to resource recycling, Clark uses a robot that has been used for decades in some industries. Launched in 2016, Clark is improving its recycling capabilities, holding up to 60 boxes per minute with absolute accuracy. Clark is scheduled to see images in boxes containing active 
logos and package printing at the next round of screening and capture. The Clark system is capable of modifying faster than humans, diverting materials for recycling, which eventually turn into trash cans. For the organization, Clark's display system combines employee ability to visualize and plan new content, while filtering in close-ups can make a difference in reception (Kite-Powell, 2017).

Plastic recycling is one of the tasks that robots do when building a fully automated home. The laser-powered laser was developed by the Advanced Research Center for Photonics at the University of Osaka. It accurately measures the appearance of different plastics so that they are different. It works best with a complex laser system. The most commonly used plastics in cannabis packaging are.

Table 2: How to recycle cannabis packaging

\begin{tabular}{|l|l|l|l|l|}
\hline $\begin{array}{l}\text { Polymer } \\
\text { name }\end{array}$ & $\begin{array}{l}\text { Polyethylene } \\
\text { Terephthalate } \\
\text { (PET) }\end{array}$ & $\begin{array}{l}\text { High density } \\
\text { polyethylene } \\
\text { (HDPE) }\end{array}$ & $\begin{array}{l}\text { Low density } \\
\text { polyethylene } \\
\text { (LDPE) }\end{array}$ & $\begin{array}{l}\text { Polypropylene } \\
\text { (PP) }\end{array}$ \\
\hline Recyclable & YES & YES & $\begin{array}{l}\text { Only accepted } \\
\text { at certain } \\
\text { facilities }\end{array}$ & $\begin{array}{l}\text { Many recycling } \\
\text { programs do not } \\
\text { accept these plastics }\end{array}$ \\
\hline $\begin{array}{l}\text { Commonly } \\
\text { repurposed } \\
\text { to make }\end{array}$ & $\begin{array}{l}\text { Textiles such as } \\
\text { carpets, pillow } \\
\text { stuffing, life } \\
\text { jackets }\end{array}$ & $\begin{array}{l}\text { Picnic tables, } \\
\text { plastic } \\
\text { lumber, } \\
\text { waste bins }\end{array}$ & $\begin{array}{l}\text { Plastic lumber, } \\
\text { landscaping } \\
\text { boards, floor } \\
\text { tiles }\end{array}$ & $\begin{array}{l}\text { Ice scrapers, brooms } \\
\text { and battery cables }\end{array}$ \\
\hline
\end{tabular}

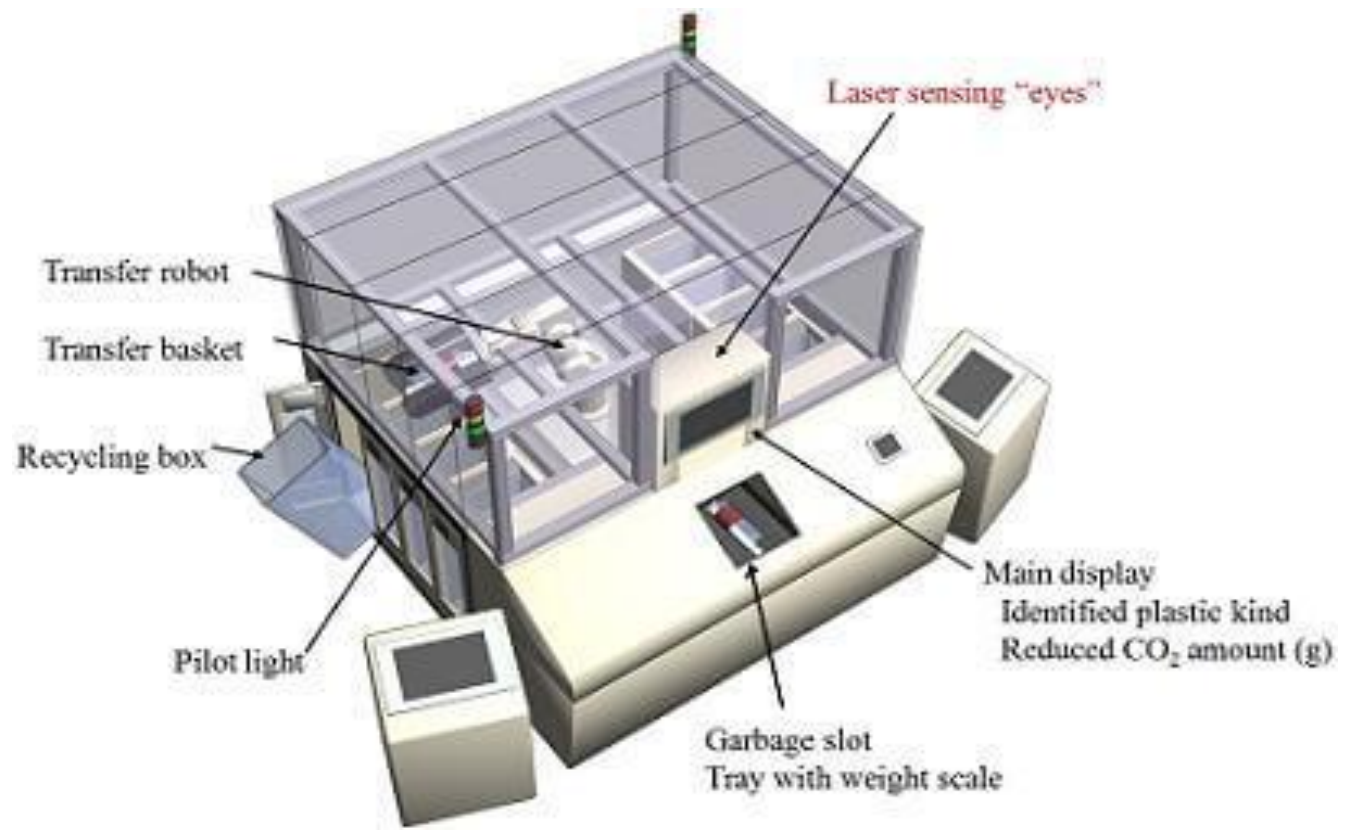

Figure 2: Robot in Japan helps to save the environment by sorting plastic using laser

Robots pulled cables from the floor, cleaned windows and cleaned food. Slowly but surely these machines are looking for things on your to-do list. Although most home robots do not have the speed or accuracy of their industrial rivals, they can handle the complex needs of 
the family. What amazes our forefathers who saw the future in the 1950s is that these robots are very rare, lack good personality and still need good human communication? Some people, like dishwashers, don't even think they are robots. When the robot arrived, we knew the idea that it should be handled by non-human bots.

\section{SamurAI sorts recyclable objects faster than humans}

One such solution is the new robot technology samurAI developed by Machinex. The robot was unveiled at the Waste Expo conference in Las Vegas earlier this year. This filtering robot uses Artificial Intelligence (AI) to detect objects in the moving belt. It can be found in recyclable items such as boxes, plastic bottles and containers. Once the robot detects an object, remove it using the suction file and place it in the appropriate container. Compared to the crew, the samurAI works much better. While the regular test has 35 options per minute, the filter robot can do up to 70 per minute. This significantly reduces operating costs and improves overall productivity.

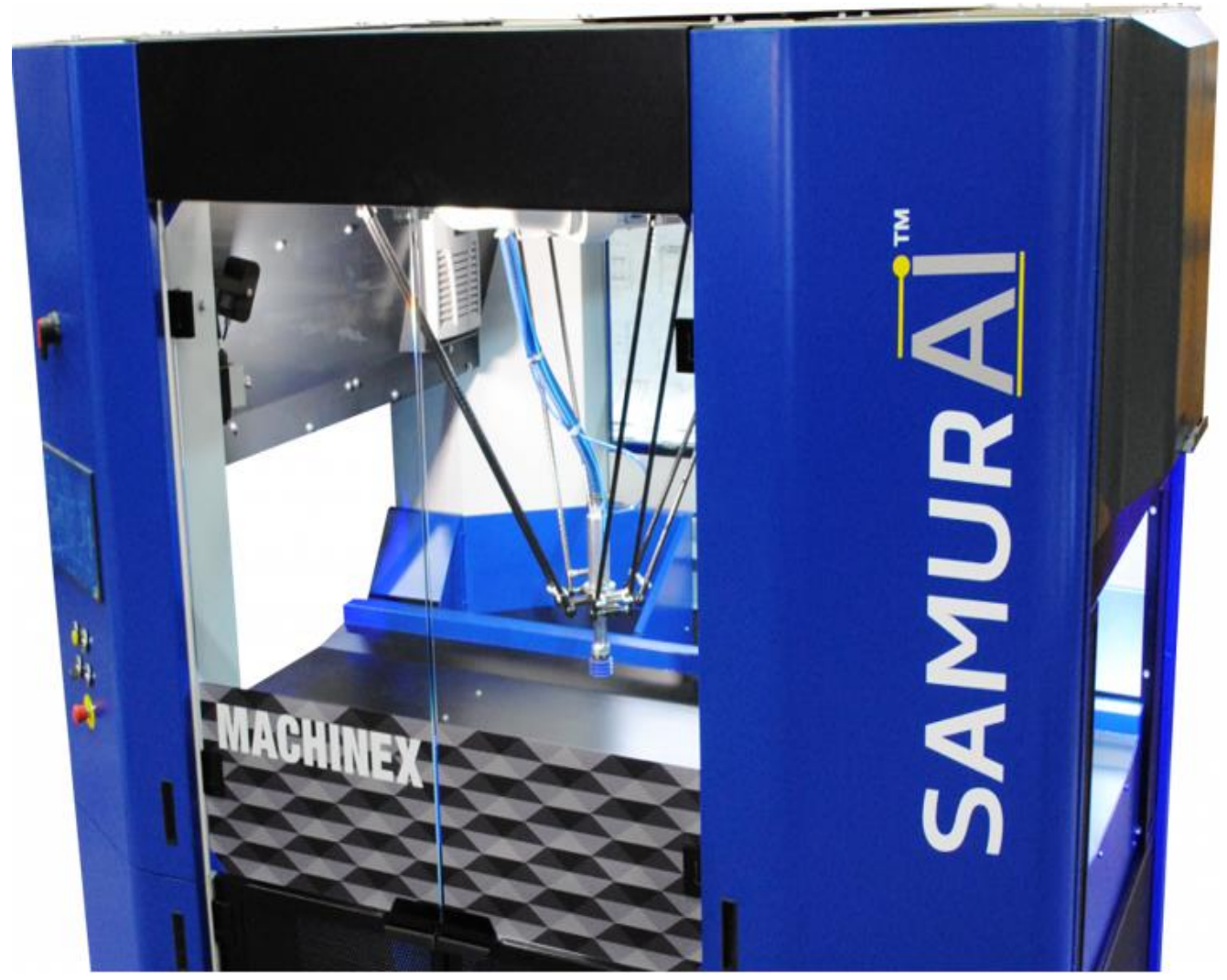

Figure 3: SamurAI robot

Some recycling companies have already seen samurAI power. For example, Lockshore Recycling Systems, a leading recycling company in Illinois, has already installed this smart robot in a reusable location in Forest View, Illinois. This robotic company that converts two human employees saves between $\$ 120,000$ and $\$ 130,000$ per year. Alan D., Company CEO. Handley explained that SamurAI helps the company play an active role in protecting the land and providing new and environmentally friendly solutions and solutions. 


\section{TrashBot does the Recycling for us}

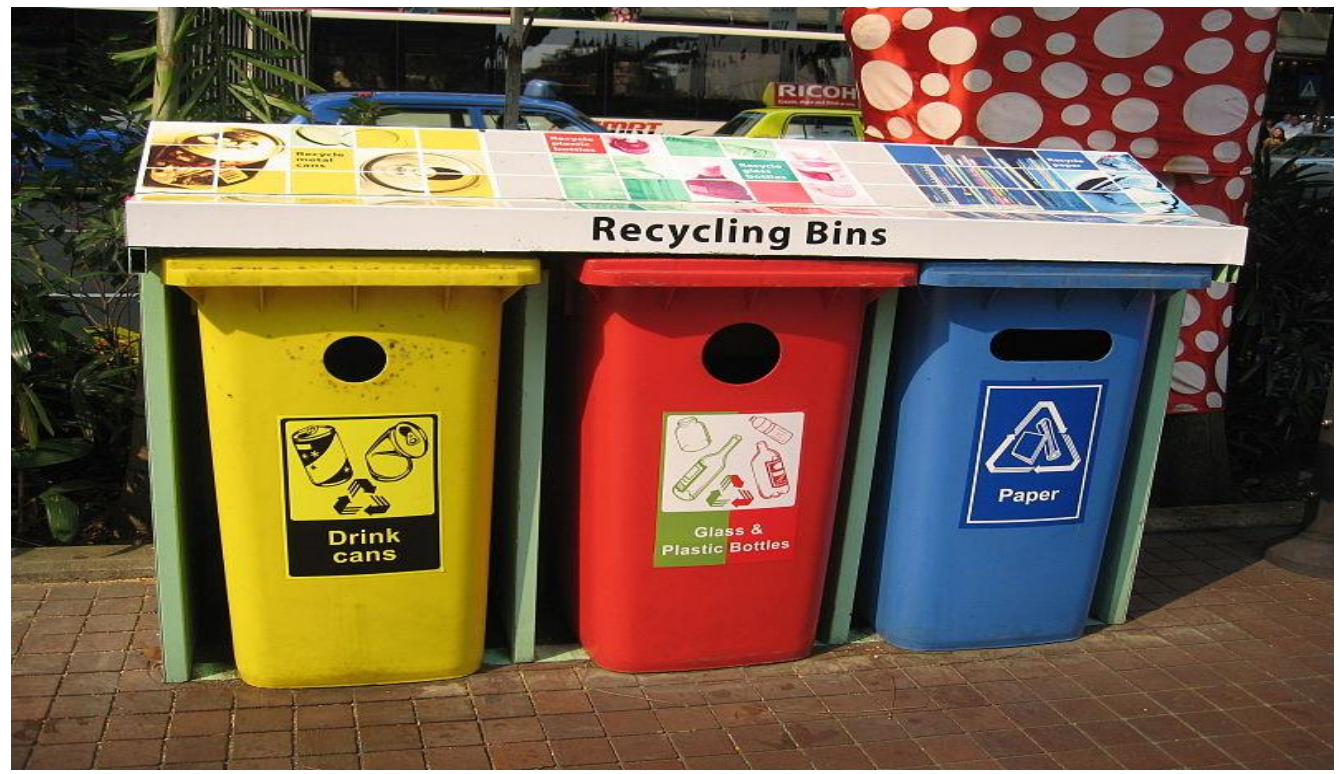

Figure 4: Trashbot automatically separates recyclables from garbage

Such issues led to the launch of Pittsburgh on a clean robotic basis to improve Trashbot. Trashbot is embedded with the robot trash can system empowered by AI. When someone throws an object into a tank, the computer detects the type of object using the power of sensors and machine learning. It can be re-measured with $90 \%$ accuracy, any fluid can be extracted and placed in the right tank. The trash boat is ideal for large and dense areas that produce a lot of waste, such as shopping malls, stadiums and airports. In the future, Clean Robotics plans to install LEDs in the system to let the user know if the discarded item has been recycled.

Recycling is likely to increase in the future as consumers become more aware of the environment and explore ways to reduce carbon emissions. However, at the same time, recycling systems are ready to go. If consumers want eco-friendly options, they also want readiness. In fact, there is evidence that people are reluctant to use it again as companies shrink complex systems. AI technology no longer completely filters repetitive objects. However, it can improve efficiency in waste management organizations and reduce the burden on employees

\section{Performance Upgrades}

The problem with our industry is that you can put everything in this conveyor belt. The machine detects a wide variety of objects as a whole and in bulk. It allowed us to use robots on earth and use artificial intelligence to detect construction materials.

Intelligence and machine learning are key areas of technology that support the modern operation of MRF automation. Unlike other industrial robots designed to create repetitive tasks, robot architecture uses AI-enabled "vision" to improve their performance. 
Visual publishing programs and diagnostic programs have increased significantly from previous editions. Most modern systems use "vision" to collect visual data with high focus or 3D cameras. Cameras detect different colors, shapes, sizes and dimensions of objects. The use of multiple features eliminates the challenges with older devices, i.e. the complexity of the infrared settings by choosing a flat screen display, black and white, blurred images or black plastic.

Many advanced filtering devices have multiple sensors and cameras and the data collected from the devices can be analyzed to maximize line performance. Automated editors can identify specific objects and see how they fit into the system. They compared new and historical data and data from different parts of the machine. Some providers report adding anonymous user data to their database for further analysis and allowing users to learn how their streams compare with industry-leading trends (Pyzyk, 2019).

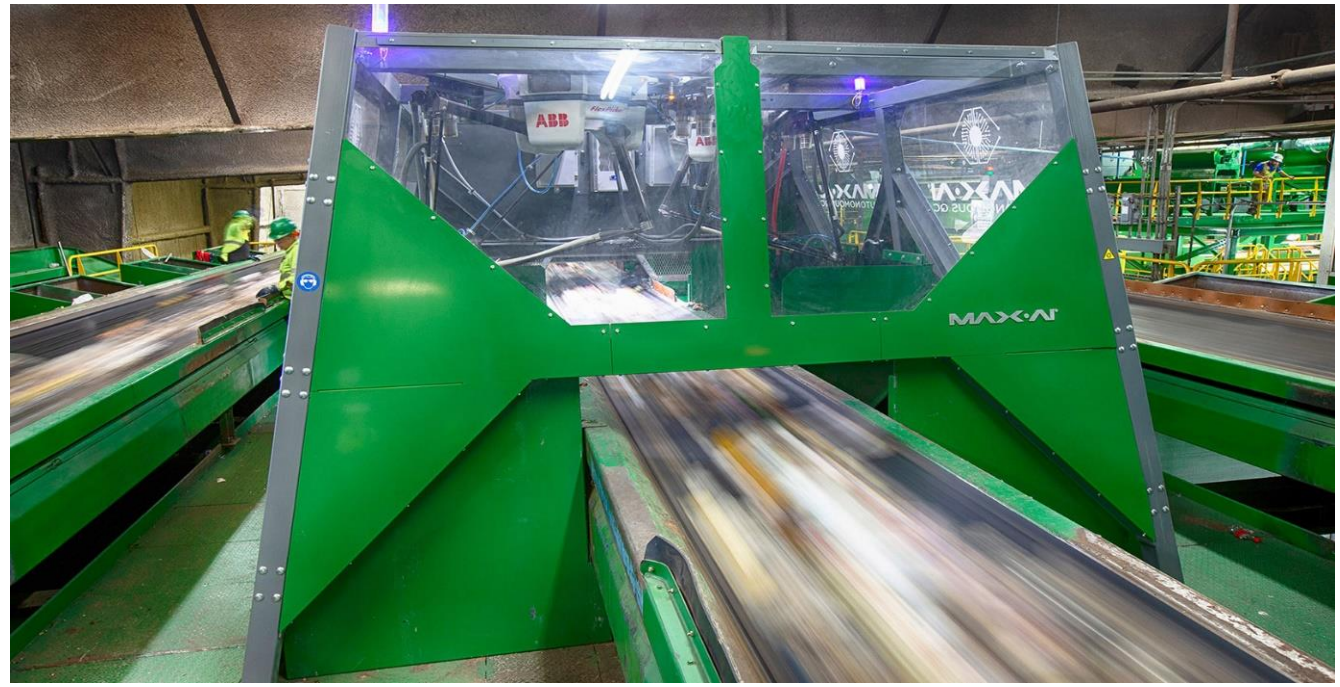

Figure 5: Bulk Handling Systems Max-AI units are among a growing number of technologies

Robots are not generally considered an alternative to visual filtering, but the system can work collaboratively to achieve high quality production. They are usually installed after suspension to control quality. Robots have simpler requirements than filters designed for operating conditions, including belt speed. They usually use suction cups to pick up objects, but some species use moving cones or finger-shaped cones.

Industry participants estimate that the average person will pick 20 to 40 per minute, depending on the size of the object and the number of robots will be more or less than that number. The manufacturers claim that previous models have 40 to 60 options per minute, while newer models have 60 to 80 options per minute.

\section{Why is this Necessary?}

Events in the labor market, especially rising wages and unemployment are making robotic investments more attractive. According to MRF operators, machines choose to fill gaps with empty filters and find it difficult to fill in other ways. 
Higher increases the cost of hiring wage agencies and the cost to employers of hiring and training new employees. Promoting employee satisfaction is known to be appropriate for retaining senior employees and, therefore, it has consistently reduced recruitment and recruitment costs. MRFs, which have automated line filters, can send employees to efficient and desirable jobs such as machine repair specialists or automated equipment management.

Machines can execute multiple shifts, lose focus, require no rest days and require no fatigue or rest. Only with that metric, in the opinion of experts, can at least one robot perform the work of two people in different shifts. This is a big challenge when you consider the fact that you can find employees in exceptional changes. In some cases, MRFs also experience variations in asset and seasonal fluctuations, while automation volatility mitigates the challenges associated with such declines. It runs in the background when we do other things. It is a sustainable, reliable and able reversible path to diversity.

Because they teach people to look at different structures, AI machines allow them to learn how to identify individual objects. Customers said automation improves MRF performance, quality and installation. It also provides reliable, consistent results.

We get the same amount of products processed by our robot system for less time and less staff than we used our manual method. The program always learns in its work to go smart, identify the best ones or decide where to find the best ones. Most devices already in use can travel on those technological waves. There is no risk of being caught by the last generation robot. There is really no reason to postpone it as long as ROI is with them today.

Another reason to use MRF filter lines is safety. Waste streams, conveyors and processing equipment create a mature environment that poses health and safety hazards. It is better for employees to avoid contact with unripe garbage. And there is no need to punch the robot.

\section{CONCLUSION}

The use of smart automation methods in waste management is highly feasible and time saving. Operating systems have experience in introducing machine algorithms to improve system flexibility. Early sensor data from sound testing and light transmission can distinguish between clear and implicit objects. Apart from this they are capable of cleverly separating glass, metal and plastic using sound waves. Electromagnetic sensors must be used to filter the real metal. Many companies have developed robots that recycle machine learning. Some of the potential companies in the formal investment and technology waste disposal projects in technology are Zen Robotics, Biotech and Intel.

\section{REFERENCES}

Abdoli, S. (2009). RFID Application in Municipal Solid Waste Management System. International Journal of Environmental Research, 3(3), 447-454. https://ijer.ut.ac.ir/article_98.html

Awe, O., Mengistu, R., and Sreedhar, V. (2017). Smart trash net: Waste localization and classification. http://cs229.stanford.edu/proj2017/final-reports/5226723.pdf

Chowdhury, B. \& Chowdhury, M. U. (2007). RFID based real-time smart waste management system. In Telecommunication Networks and Applications Conference, 2007. ATNAC 2007. Australasian, pages 175-180. IEEE.

Donepudi, P. K. (2018). Application of Artificial Intelligence in Automation Industry. Asian Journal of Applied Science and Engineering, 7(1), 7-20. http://doi.org/10.5281/zenodo.4146232 
Donepudi, P. K. (2015). Crossing Point of Artificial Intelligence in Cybersecurity. American Journal of Trade and Policy, 2(3), 121-128. https://doi.org/10.18034/ajtp.v2i3.493

Donepudi, P. K. (2017). Machine Learning and Artificial Intelligence in Banking. Engineering International, 5(2), 83-86. https://doi.org/10.18034/ei.v5i2.490

Islam, M. S., Arebey, M., Hannan, M., and Basri, H. (2012). Overview for solid waste bin monitoring and collection system. In Innovation Management and Technology Research (ICIMTR), 2012 International Conference on, pages 258-262. IEEE

Kite-Powell, J. (2017, April 12). This Recycling Robot Uses Artificial Intelligence To Sort Your Recyclables. Retrieved November 07, 2020, from https://www.forbes.com/sites/jenniferhicks/2017/04/04/this-recycling-robot-uses-artificialintelligence-to-sort-your-recyclables/

Parlikad, A. K. \& McFarlane, D. (2007). RFID-based product information in end-of-life decision making. Control Engineering Practice, 15(11), 1348-1363. https://doi.org/10.1016/j.conengprac.2006.08.008

Pyzyk, K. (2019, December 11). Robots move in. Retrieved November 08, 2020, from https://www.wastedive.com/news/recycling-labor-mrf-robots-move-in/568554/

Sinha, A. \& Couderc, P. (2012). Using OWL Ontologies for Selective Waste Sorting and Recycling. OWLED-2012, May 2012, Heraklion, Crete, Greece. https://hal.inria.fr/hal-00924427

Thomas, V. M. (2008). Environmental implications of RFID. In Electronics and the Environment, 2008. ISEE 2008. IEEE International Symposium on, pages 1-5. IEEE.

$$
--0--
$$

\section{How to Cite:}

Ahmed, A. A. A., \& Asadullah, A. (2020). Artificial Intelligence and Machine Learning in Waste Management and Recycling. Engineering International, 8(1), 43-52. https://doi.org/10.18034/ei.v8i1.498 